\title{
VARIAÇÃO ESPAÇO-TEMPORAL NAABUNDÂNCIA DE ORDENS E FAMÍLIAS DE MACROINVERTEBRADOS BENTÔNICOS REGISTRADOS EM ÁREA DE NASCENTE, CAMPO VERDE-MT
}

\author{
ZARDO, Daniela Cristina. Mestranda do Programa de Pós-Graduação em Recursos Hídricos, Universidade \\ Federal de Mato Grosso (UFMT). Avenida Fernando Corrêa, Cuiabá-MT. Tel: (65) 3615 8764. E-mail: \\ daniela_zardo@yahoo.com.br. \\ HARDOIM, Edna Lopes. Doutora do Departamento de Botânica e Ecologia/Instituto de Biociências/ \\ Universidade Federal de Mato Grosso. Avenida Fernando Corrêa, Cuiabá-MT. \\ AMORIM, Ricardo. Doutor do Programa de Pós-Graduação em Recursos Hídricos/Universidade Federal \\ de Mato Grosso. Avenida Fernando Corrêa, Cuiabá-MT. \\ MALHEIROS, Carolina Hortêncio. Bióloga, Mestre em recursos Hídricos pela UFMT. Avenida Fernando \\ Corrêa, Cuiabá-MT.
}

\begin{abstract}
Resumo
Os macroinvertebrados bentônicos estão entre os principais organismos utilizados na avaliação de impactos ambientais e monitoramento biológico em ecossistemas aquáticos. Adistribuição desses organismos é determinada pelo tipo e pela diversidade de habitats disponíveis para a comunidade. O presente estudo teve como objetivo contribuir com o conhecimento da distribuição de macroinvertebrados bentônicos em áreas impactadas do estado de Mato Grosso, inventariando as ordens e famílias com ocorrência em uma nascente represada em área agrícola no Município de Campo Verde-MT, analisando a estrutura da comunidade nos períodos chuvoso e de estiagem, avaliando sua abundância e riqueza. A área de estudo está localizada na nascente do Rio São Lourenço-MT, onde são cultivados soja, milheto e algodão (latitude S $15^{\circ} 37^{\prime} 18,8^{\prime \prime}$ e longitude W 55 $10^{\circ}$ " 24,8"). Em sua adjacência (ca. de 30m) foi represada uma de suas nascentes, amostrada em sua entrada (P2), na zona limnética (P3) e em sua saída (P4). Além desses três pontos, foram amostrados uma de suas nascentes (P1) e um córrego abaixo da represa (P6). Cada ponto foi amostrado seis vezes, três no período chuvoso e três no período de estiagem, com três réplicas em cada ponto. A maior ocorrência de organismos se deu no período chuvoso, com 216 organismos, nos pontos P2 e o P3. Diptera foi a mais abundante no período chuvoso, representada pela família Chironomidae.
\end{abstract}

Palavras-chave: Agricultura; Comunidade; Monitoramento biológico; Macroinvertebrados bentônicos.

SPATIAL-TEMPORAL VARIATION IN THE ABUNDANCE OF ORDERS AND FAMILIES OF BENTHIC MACROINVERTEBRATES RECORdED IN A SPRING AREA, CAMPo VERDE-MT

\begin{abstract}
The benthic macroinvertebrates are among the main organisms used in the evaluation of environmentaland biological monitoring in aquatic ecosystems. The distribution of these organisms is mainly determined by the type and diversity of habitats available to the community. This paper aims to contribute to the knowledge of the distribution of macroinvertebrates in the state of Mato Grosso, analyzing the macroinvertebrates orders and familiesoccurring in a spring dammed in an agricultural land in the municipality of Campo Verde-MT, evaluating the structure of the community in rainy and dry periods The study area is located in the headwaters of São Lourenço River - TM, where soybeans, millet and cotton (latitude $\mathrm{S} 15^{\circ} 37^{\prime} 18.8^{\prime \prime} \mathrm{W}$ and longitude $55^{\circ} 10$ '24.8") are cultivated. In its vicinity (ca. $30 \mathrm{~m}$ ) one of its sources was dammed, sampled at its input (P2) in the limnetic zone (P3) and at its
\end{abstract}


output (P4). In addition to these three points, we sampled one of its sources (P1) and a stream below the dam (P6). Each point was sampled six times, three during the rainy season and three during the dry season, with three replicates at each point. The increased occurrence of organisms occurred in the rainy season, with 216 organisms at P2 and P3 points. Diptera was the most abundant in the rainy season, represented by the Chironomidae family.

KeYwords: Agriculture; Community; Biological monitoring; Benthic macroinvertebrates.

\section{INTRODUÇÃo}

A integridade e o funcionamento dos ecossistemas aquáticos dependem da interação com o sistema terrestre. A diversidade da fauna e flora das águas continentais está relacionada com os mecanismos de funcionamento de rios, lagos, áreas alagadas e represas, tais como o ciclo hidrológico e a variedade de habitats e nichos (TUNDISI et al., 2006).

Os macroinvertebrados bentônicos são organismos que vivem parte ou todo o seu ciclo de vida no fundo dos ecossistemas aquáticos, associados a diversos substratos, tanto orgânicos quanto inorgânicos. Sua distribuição e diversidade são diretamente influenciadas pela estrutura do sedimento, quantidade de detritos orgânicos, mudanças do substrato e da água em decorrência dos períodos sazonais; e indiretamente afetadas por modificações nas concentrações de nutrientes e mudanças na produtividade primária (WARD, 1992). Constituem um dos grupos biológicos mais diversificados e abundantes dos ambientes aquáticos, constituindo importante fonte de energia para níveis tróficos superiores, tanto em cadeias alimentares de pastoreio quanto de detritos.

O regime de chuvas é um fator ambiental importante na dinâmica de organização e estrutura das comunidades aquáticas. Ele afeta alguns dos principais parâmetros associados à distribuição de espécies como vazão, entrada de matéria orgânica nos corpos d'água, estabilidade e disponibilidade de microhabitats (EGLER, 2002).
As atividades humanas caracterizadas como impactantes são aquelas que promovem distúrbios nesse equilíbrio dinâmico, sendo capazes de afetar em alguma escala o funcionamento dos ecossistemas. A magnitude de umimpacto é proporcional a sua frequência, extensão espacial e duração temporal. Os maiores impactos são aqueles que afetam a resiliência dos sistemas, impedindo o restabelecimento da condição ambiental e biológica anterior (CLEMENTS, 2000).

A agricultura é apontada como a principal responsável pelos distúrbios nos ecossistemas hídricos. Entre os principais impactos associados a essa atividade destacam-se o desmatamento, a consequente erosão dos solos e a contaminação não pontual das águas por resíduos de fertilizantes e pesticidas (ONGLEY, 1997).

O presente estudo teve como objetivo contribuir com estudos de distribuição de macroinvertebrados bentônicos no estado de Mato Grosso, inventariando as ordens e famílias de macroinvertebrados com ocorrência emuma nascente represada emárea agrícola no Município de Campo Verde-MT, analisando a estrutura da comunidade nos períodos chuvoso e de estiagem, avaliando sua abundância e riqueza.

\section{Material e Métodos}

\section{Área de estudo}

O Município de Campo Verde (Figura 1) localizase no sudeste do Mato Grosso e a $190 \mathrm{~km}$ ao leste de Cuiabá com latitude S15³3'17" e longitude W55 $10^{\circ} 25^{\prime \prime}$, com altitude de $736 \mathrm{~m}$ e área de $4.744,5 \mathrm{~km}^{2}$. O solo é basicamente constituído de latosolo vermelho escuro e areias quartzozas hidromórficas. A área está inserida no relevo do Planalto dos Guimarães, Serra dos Coroados, Serra do Roncador e nas Bacias do Araguaia-Tocantins e na do Prata. O clima é tropical com temperatura variando entre $18^{\circ}$ a $24^{\circ} \mathrm{C}$, com máxima de $34^{\circ} \mathrm{C}$. Possuem duas estações bem definidas, a da seca (de junho a setembro) e a das chuvas (de outubro a maio), e a precipitação corresponde de $9,4 \mathrm{~mm}$ a $25 \mathrm{~mm}$ (SILVA, 2004). É banhado pelos rios São Lourenço, Rio das Mortes, Aricá Mirin, Cumbica, Roncador, Ximbica, Galheiros e da Casca. Sua economia provém 
de diversos setores, sendo o plantio de soja que colocam o município em destaque nacional (75.000ha), algodão (60.416ha) e milho (26.000ha) (RODRIGUES et al., 2005).

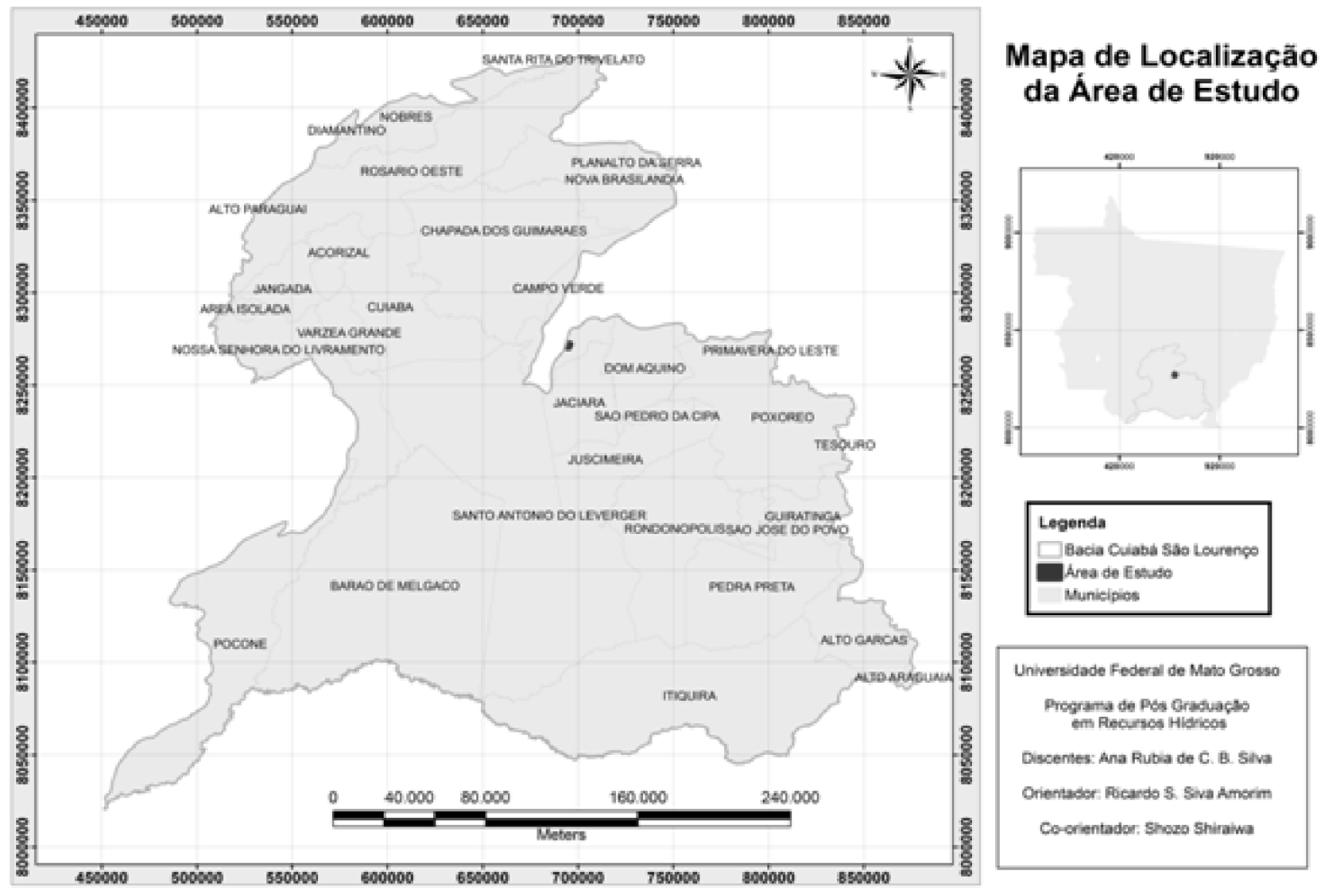

Figura 1 - Mapa da localização do município de Campo Verde e área de estudo definida numa Fazenda em Campo Verde, Mato Grosso. Escala: 1: 3.500.

Fonte: Bonilha (2011).

A área de estudo está localizada na nascente do Rio São Lourenço-MT, microbacia hidrográfica do alto rio São Lourenço, próxima à área urbana do município de Campo Verde. Essa área está intensamente ocupada pela agricultura, em vários locais a mata ciliar é inexistente e ocorre ocupação pela agricultura das cabeceiras de drenagem de diversos córregos que formam este rio.

\section{Área de coleta}

A área de coleta das amostras localiza-se em uma fazenda no Município de Campo Verde-MT, onde são cultivados soja, milheto e algodão. Em sua adjacência (ca. de $30 \mathrm{~m}$ ) foi represada uma das nascentes do Rio São Lourenço (latitude S 15 37' 18,8" e longitude W 55¹0" 24,8", sistema WGS84) que foi amostrada em sua entrada (P2), na zona limnética (P3) e em sua saída (P4). Além desses três pontos, foi amostrada uma das nascentes do Rio São Lourenço (P1), e um córrego abaixo da represa (P6), conforme apresentado na Figura 2.

O estudo foi realizado em dois períodos sazonais, correspondendo à estação chuvosa e à estiagem na região. 


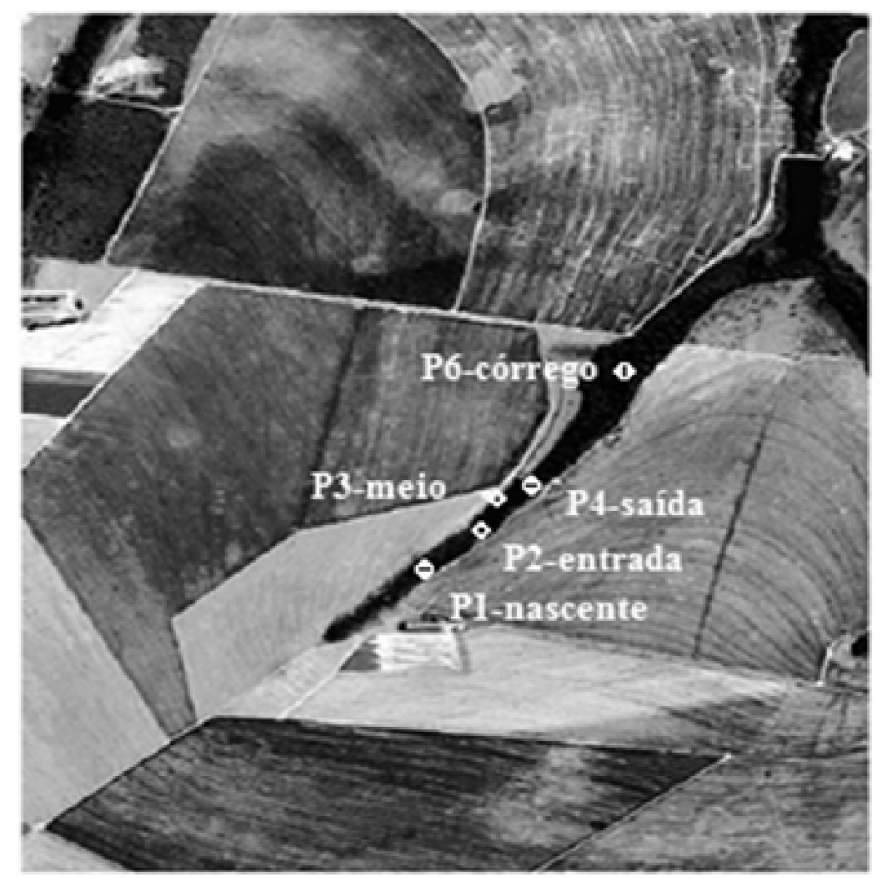

Figura 2 - Pontos de coleta definidos numa Fazenda em Campo Verde, Mato Grosso (Google Earth, 2009). Escala: 1:3.500.

Fonte: BONILHA(2011).

\section{Descrição dos Pontos de coleta}

O P1 é o ponto referente à nascente do rio São Lourenço. Com aproximadamente $40 \mathrm{~cm}$ de profundidade, caracteriza-se pela presença da mata ciliar, muita vegetação e serrapilheira, apresentando pouca luminosidade.

$\mathrm{O} \mathrm{P} 2$ e o $\mathrm{P} 3$, pontos referentes à represa, apresentam aproximadamente 1,40 m e 1,70 m de profundidade, respectivamente. Caracterizam-se pela ausência da mata ciliar e abundância de macrófitas aquáticas e troncos de árvores ao fundo. O P4 refere-se à saída da represa. Com cerca de 1,20 m de profundidade, caracteriza-se por ser a área mais aberta do local estudado, com ausência da mata ciliar e pouca vegetação.

O P6 refere-se ao córrego a jusante da represa. Com aproximadamente $60 \mathrm{~cm}$ de profundidade, caracteriza-se pela presença de mata ciliar, muita vegetação e serrapilheira e com pouca luminosidade.

\section{Coleta e análise dos dados}

Para coletas de sedimento foi utilizada uma draga de Petersen com área amostral de $0,0375 \mathrm{~m}^{2}$. Cada ponto foi amostrado seis vezes, três no período chuvoso (novembro/2009, janeiro e março de 2010) e três no período de estiagem (maio, julho e setembro de 2010), com três réplicas em cada ponto, totalizando uma área amostral de $0,225 \mathrm{~m}^{2}$.

As coletas das amostras na represa foram feitas em três estações amostrais - P2, P3 e P4, localizadas em duas extremidades (P2 e P4) e na região central da represa $(\mathrm{P} 3)$, integrando-se as amostras da margem direita e esquerda.

As amostras foram acondicionadas em sacos plásticos e adicionado álcool $96 \%$ para preservação até chegar ao laboratório de Ecologia Aquática da Universidade Federal de Mato Grosso (UFMT), onde foram lavadas sobre peneiras com abertura de malhas de 1,00, 0,50 e 0,25 mm. Após serem lavadas, as amostras foram triadas e identificadas com auxílio de um microscópio estereoscópico e fixadas com álcool 
$70 \%$. Os exemplares foram identificados até o nível de família (MERRITT \& CUMMINS, 1996) no laboratório LATEMAS/IB-UFMT.

As amostras para análise de granulometria e de matéria orgânica foram coletadas nos pontos determinados (aproximadamente $300 \mathrm{~g}$ de sedimento), coletados com a draga Petersen e colocados em sacos plásticos estéreis devidamente identificados e resfriados até o processamento em laboratório. As análises foram realizadas no laboratório de Física do Solo e Fertilidade do Solo da Faculdade de Agronomia e Medicina Veterinária-FAMEV (UFMT).
Para análise dos resultados foi considerada a abundância de organismos, buscando quantificar o número de indivíduos das ordens e famílias presentes nas amostras em cada período amostral (RICKLEFS, 2003). Calculou-se a correlação de Sperman entre as variáveis bióticas e abióticas.

\section{Resultados e Discussão}

Os teores de areia e silte foram maiores no período chuvoso em todos os pontos amostrais, o que pode ser explicado pelo aumento do volume de água e aumento da correnteza (Figura 3).

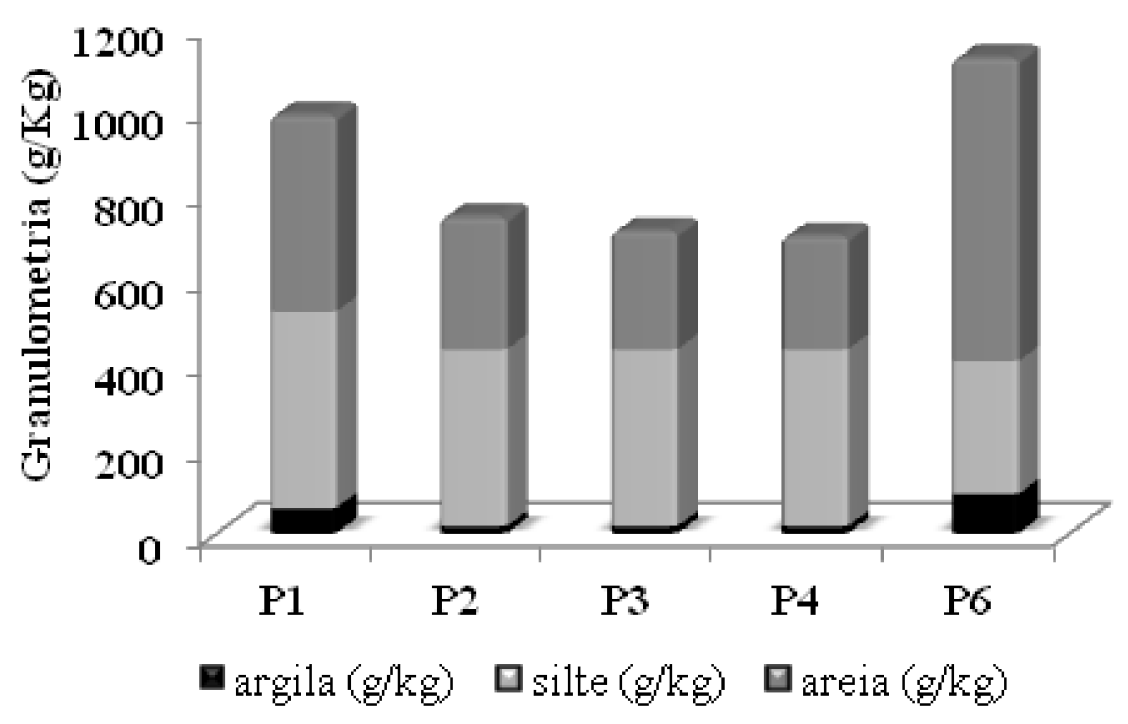

Figura 3 - Média dos resultados de Granulometria nos pontos amostrais no período chuvoso.

Fonte: Dados de Pesquisa.

No período de estiagem, a concentração de argila e areia foram maiores em todos os pontos amostrais, conforme demonstrado na Figura 4. 


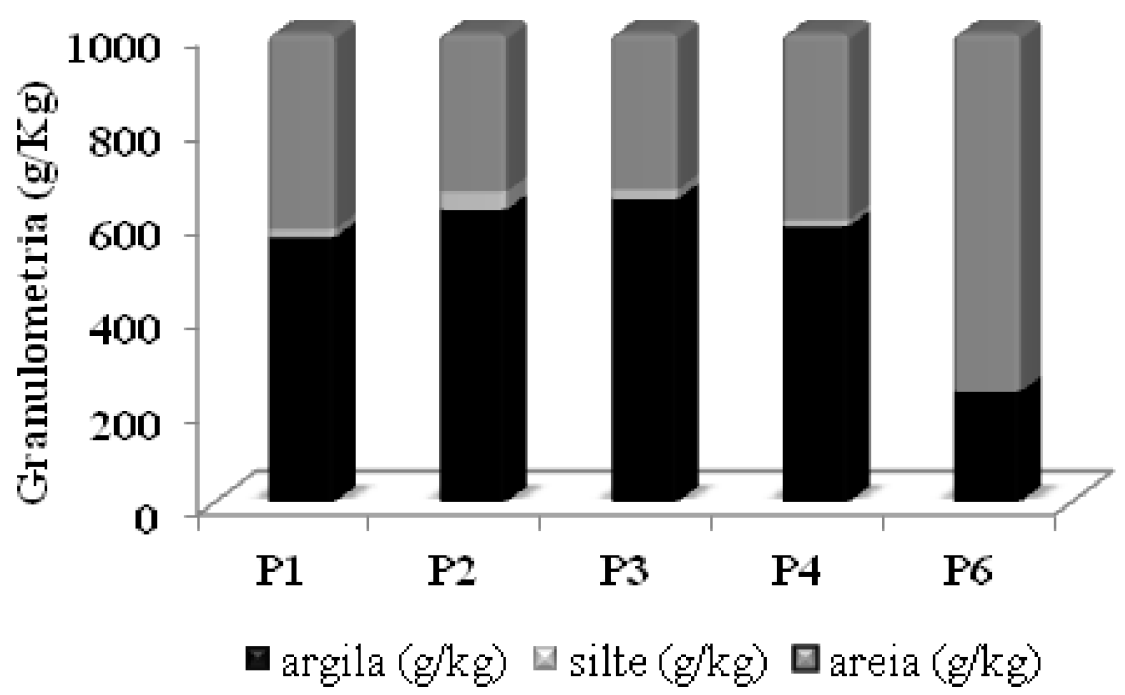

Figura 4 - Média dos resultados de Granulometria nos pontos amostrais no período de estiagem.

Fonte: Dados de Pesquisa.

O P6 foi o único ponto que apresentou maior quantidade de sedimento fino, nos períodos estudados. Isto deve estar relacionado com processos erosivos mais intensos nos pontos a montante com consequente aporte de sedimentos carreados dos solos para dentro do corpo d'água. Para Allan (1995), o substrato, em geral, tem a tendência de diminuir de tamanho de partícula em direção a jusante.

Nos pontos P2, P3 e P4 houve predominância do tipo granulométrico argila; segundo Callisto; Esteves (1996), essa frequência está relacionada com áreas impactadas, com ausência de mata ciliar.

Nos últimos anos, tem sido cada vez mais importante a análise do sedimento na avaliação da qualidade dos ecossistemas aquáticos. Tradicionalmente esse compartimento tem sido considerado importante nos processos de (geo) acumulação, com significância histórica para a bacia de drenagem. Atualmente, também temimportância reconhecida nos processos de reutilização de materiais autóctone e alóctone e de trocas e/ou interações de diferentes espécies químicas com a coluna d'água e a biota residente (HÅKANSON; JANSSON, 1983; MOZETO et al., 2006).

Billy et al. (2000), estudando o impacto da agricultura em riachos de cabeceira na França, encontraram significante variação da granulometria no sentido montante jusante. Moretti; Calisto (2005) encontraram, na bacia do rio Doce (MG), composição granulométrica do sedimento dos rios formada de areia média e grossa, e atribuíram o fato à erosão e remoção de florestas das margens.

Em relação à matéria orgânica, observam-se na Figura 5 os pontos referentes à represa (P2, P3 e P4): a concentração foi maior no período chuvoso, o que pode estar relacionado com a presença de macrófitas nesses pontos, principalmente no P2 e P3. No P1 (nascente) e no P6 (córrego a jusante da represa) observa-se que a concentração de matéria orgânica foi maior no período de estiagem, o que pode estar relacionado com a mata existente ao redor desses cursos d'água. 


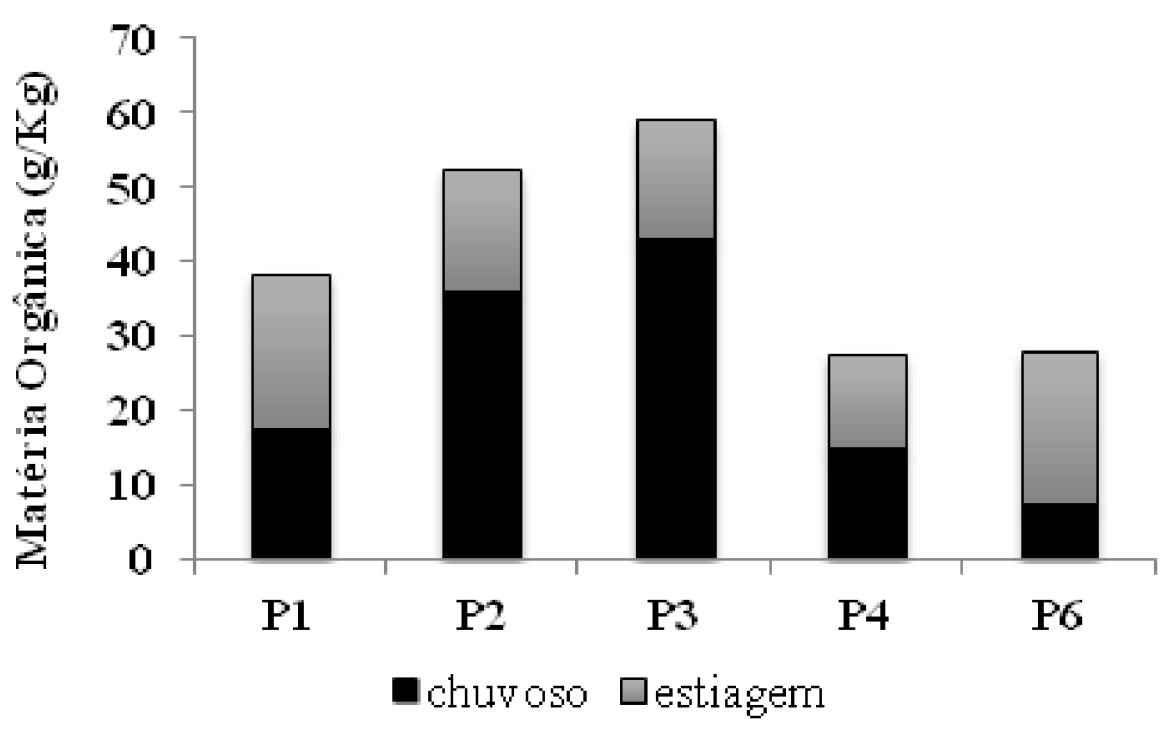

Figura 5 - Média dos resultados de matéria orgânica nos pontos amostrais nos períodos chuvoso e de estiagem.

Fonte: Dados de Pesquisa.

Wetzel (1975) cita que a fauna bentônica é muito diversificada, sendo extremamente heterogênea em lagos e outros corpos d'água, em função das variações das condições necessárias para alimentação, crescimento e reprodução. Segundo o autor, essas condições podem ser fortemente influenciadas pelas mudanças do substrato e da água, em decorrência dos períodos sazonais e da introdução de matéria orgânica que pode ser usada para alimentação, sendo uma variável de extrema importância para compreender a dinâmica das comunidades em um corpo hídrico.

Em relação aos invertebrados, foram coletados macroinvertebrados bentônicos pertencentes ao filo Arthropoda, da classe Insecta. Foram observadas nas amostras seis ordens durante o período estudado (Tabela1). 
Tabela 1 - Abundância absoluta por família dos macroinvertebrados bentônicos coletados nos pontos amostrais durante o período de estudo (nov/09, jan/10 e mar/10, maio/10, julho/10 e set/10).

\begin{tabular}{|c|c|c|c|c|c|c|}
\hline \multirow[t]{2}{*}{ Táxon } & \multicolumn{6}{|c|}{ Estações amostrais } \\
\hline & $\mathbf{P 1}$ & $\mathbf{P 2}$ & $\mathbf{P 3}$ & $\mathbf{P 4}$ & P6 & Total \\
\hline \multicolumn{7}{|l|}{ Diptera } \\
\hline Chironomidae & 29 & 74 & 73 & 38 & 10 & 224 \\
\hline Ceratopogonidae & 01 & 11 & 21 & 9 & - & 42 \\
\hline Tabanidae & 01 & & & & & 01 \\
\hline \multicolumn{7}{|l|}{ Coleoptera } \\
\hline Dytiscidae & - & 5 & 4 & - & - & 9 \\
\hline Elmidae & 01 & 5 & 6 & - & 4 & 16 \\
\hline Hydrophilidae & - & 3 & 2 & - & - & 5 \\
\hline Hexacyloepus & - & - & 21 & - & - & 21 \\
\hline \multicolumn{7}{|l|}{ Ephemeroptera } \\
\hline Leptophlebiidae & & 1 & 1 & & & 2 \\
\hline Baetidae & & 1 & 2 & 1 & & 4 \\
\hline Leptohyphidae & & & 2 & & & 2 \\
\hline \multicolumn{7}{|l|}{ Tricoptera } \\
\hline Hydropsychidae & 1 & - & 2 & - & 1 & 4 \\
\hline Hydroptilidae & 1 & - & 1 & 1 & - & 3 \\
\hline Leptoceridae & - & 1 & 1 & - & - & 2 \\
\hline \multicolumn{7}{|l|}{ Odonata } \\
\hline Libellulidae & - & 3 & 2 & - & 2 & 7 \\
\hline \multicolumn{7}{|l|}{ Acari } \\
\hline Hydracarinae & - & - & 4 & - & - & 4 \\
\hline Total & 34 & 103 & 143 & 49 & 17 & 346 \\
\hline
\end{tabular}

Fonte: Dados de Pesquisa. 
A maior abundância de organismos se deu no período chuvoso, com 216 indivíduos coletados. Isso se deve pela chegada das chuvas, o que provoca o carreamento de material de origem alóctone. Com o aumento do material carreado, do volume de água e da profundidade, se elevou, também, o número de habitats disponíveis para os macroinvertebrados bentônicos. Com isso, houve o favorecimento de um número maior de organismos colonizando o sedimento nesse período.

A ordem Diptera foi a mais abundante nos períodos estudados (chuvoso e estiagem), com 267 indivíduos capturados. Os resultados obtidos mostram variações temporais e espaciais na comunidade bentônica. A abundância de indivíduos foi maior durante o período chuvoso em relação ao período de estiagem e variou, também, de acordo com fatores abióticos e bióticos nos locais de amostragem.

Os pontos amostrais onde foram registradas as maiores abundância de organismos no período chuvoso foram o P2 e o P3, caracterizados como entrada e meio da represa, com 92 e 12 organismos coletados respectivamente (Figura 6). No período de estiagem, os pontos amostrais com maior abundância de organismos foram o $\mathrm{P} 3$ e o $\mathrm{P} 4$, caracterizados como meio e saída da represa, com 36 e 42 organismos coletados, respectivamente (Figura 7). Nos pontos em questão foi encontrada uma maior concentração de sedimentos argilosos nesse período, ricos em detritos orgânicos representados, principalmente, por restos de vegetação, o que pode servir de alimentação para esses organismos.

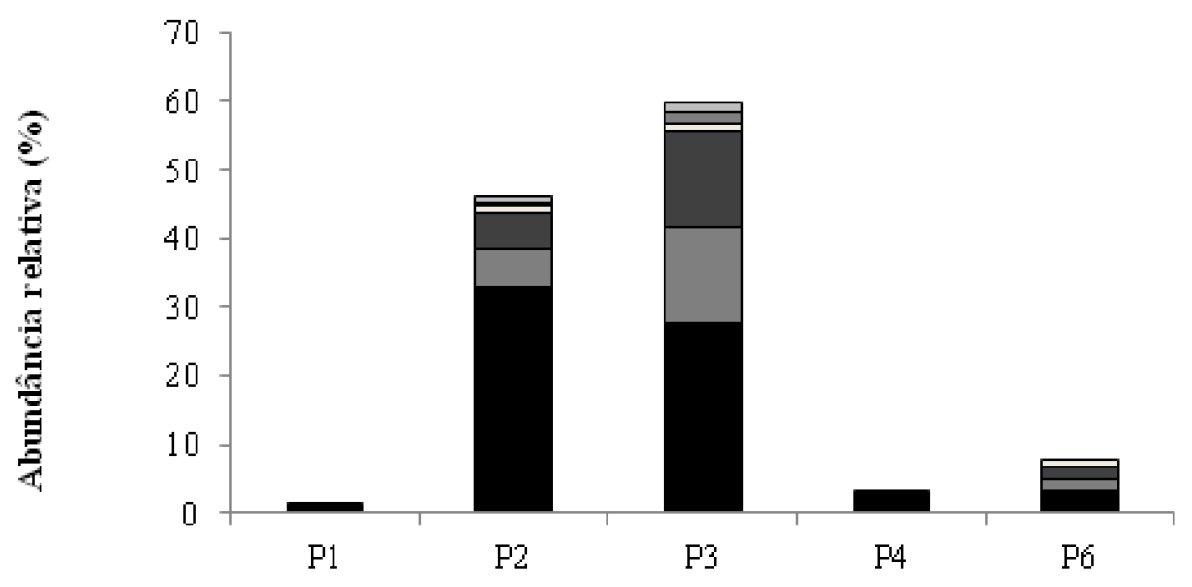

Diptera $\square$ Coleoptera $\square$ Ephemeroptera $\square$ Odonata $\square$ Tricoptera $\square$ Chelicerata

Figura 6 - Abundância relativa dos grupos taxonômicos coletados ao longo das estações amostrais no período chuvoso.

Fonte: Dados de Pesquisa. 


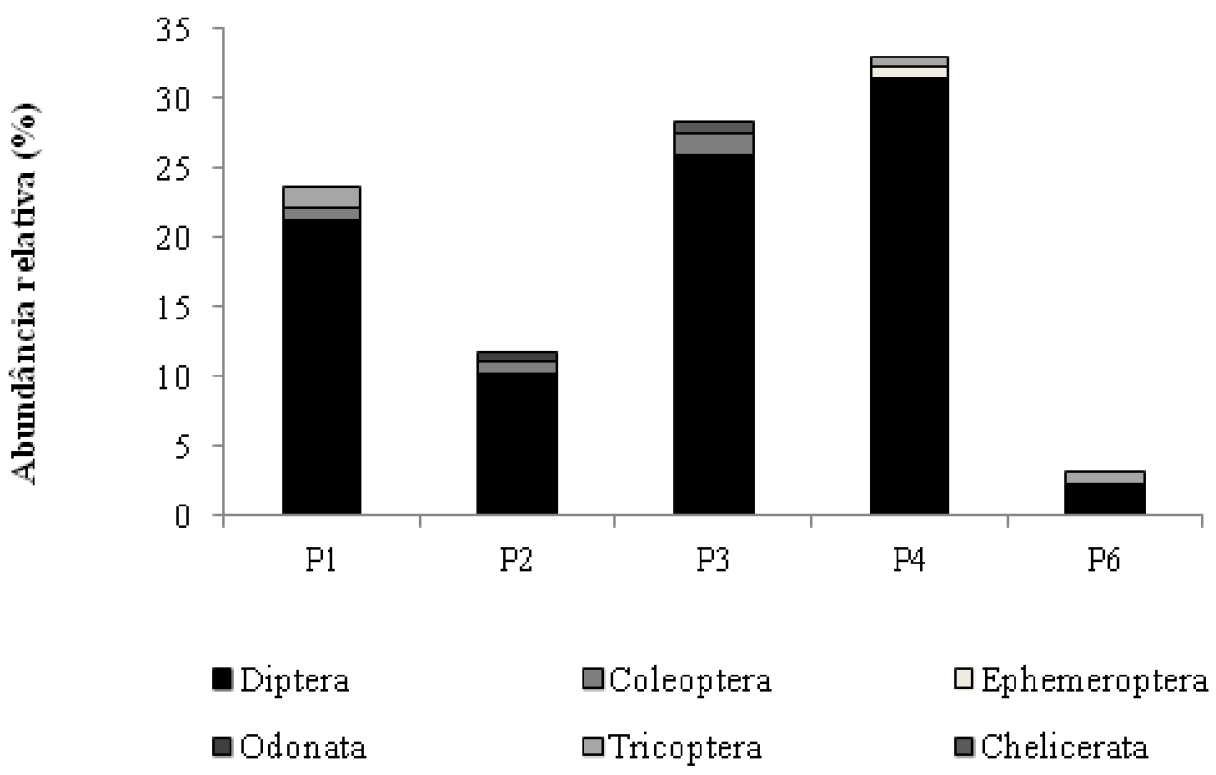

Figura 7 - Abundância relativa dos grupos taxonômicos coletados ao longo das estações amostrais no período de estiagem.

Fonte: Dados de Pesquisa.

Dos 346 organismos coletados, as famílias mais frequentes foram Chironomidae $(64,3 \%)$ e Ceratopogonidae $(12,06 \%)$ da ordem Diptera; Elmidae $(4,59 \%)$ e Dytiscidae $(2,58 \%)$ da ordem Coleoptera.

A família Chironomidae constitui um grupo importante sob o ponto de vista ecológico. $\mathrm{O}$ fato de apresentarem ampla distribuição na maioria dos ecossistemas aquáticos e ocorrer em alta densidade e riqueza (HIRABAYASHI \& WOTTON, 1998 apud ABURAYA \& CALLIL, 2007), além de possuírem hábitos sedentários, capacita este grupo a refletir sobre as mudanças ecológicas locais (CALLISTO \& ESTEVES 1998, GOULART \& CALLISTO 2003). Em relação à abundância da família Chironomidae, algumas espécies são consideradas sensíveis e outras tolerantes aos impactos provenientes dos múltiplos usos do solo. Entretanto, é reconhecida a supremacia desse grupo em locais expostos a interferências antrópicas, como o desmatamento e a entrada de poluentes inorgânicos, por exemplo, agrotóxicos lixiviados de campos agrícolas (CORBI et al., 2006), o que pode explicar a grande abundância desse grupo nos pontos amostrais estudados.

Organismos das ordens Ephemeroptera e Tricoptera, conhecidos por serem indicadores de melhor qualidade de água, foram encontrados nos pontos P2 e P3 no período chuvoso e P1 e P4 no período de estiagem. A ocorrência desses organismos na área aberta da represa (P2, P3 e P4) pode ser explicada pela grande concentração de argila e matéria orgânica no sedimento e pela existência de macrófitas nas margens, que pode servir como alimento e abrigo. Já no P1, a existência da mata ciliar proporciona uma maior diversidade de habitats para esses organismos.

$\mathrm{Na}$ análise de correlação de Sperman, observa-se uma correlação significativa entre matéria orgânica e a maioria das ordens encontradas; Dipetera $(r=0,251)$, Coleoptera $(r=0,554)$, Ephemeroptera $(r=0,554)$ e Tricoptera $(\mathrm{r}=0,453)$. Wetzel (1983) cita que a fauna bentônica é muito diversificada sendo extremamente heterogênea em lagos e outros corpos d'água em função 
das variações das condiçõos necessárias para alimentação, crescimento e reprodução. Segundo este autor, essas condições podem ser fortemente influenciadas pelas mudanças do substrato e da água, em decorrência dos períodos sazonais e da introdução de matéria orgânica que pode ser usada para alimentação, sendo uma variável de extrema importância para compreender a dinâmica das comunidades em um corpo hídrico.

Roque et al. (2003), Brito Júnior (2003) e Oliveira (2009) encontraram maior abundância de larvas de Diptera em locais com maior quantidade de matéria orgânica, Egler (2002) encontrou maior abundância de tricoptera e coleoptera no período chuvoso, relacionando a ocorrência de chuva com o maior aporte de matéria orgânica para o curso d'água.

\section{Conclusão}

Atribui-se a maior abundância e riqueza de invertebrados amostrada em área aberta da represa (P2 e P3) a uma maior quantidade de material alóctone transportado, onde, com a falta de vegetação ciliar, há uma maior penetração de radiação solar e, consequentemente, uma maior produção de material autóctone como algas, macrófitas e perifíton. Dessa maneira, a comunidade dos macroinvertebrados da represa disporia não somente do material alóctone, mas também da matéria orgânica e algas que afloram com a ausência do dossel, explicando os resultados encontrados.

A vasta ocorrência da ordem Diptera e da família Chironomidae pode ser considerada uma característica dos sistemas aquáticos da região ou uma consequência da condição em que esses sistemas estão inseridos. Fatores resultantes da poluição e eutrofização como matéria orgânica dissolvida, nutrientes em excesso e presença de substâncias tóxicas afetam consideravelmente a comunidade de macroinvertebrados bentônicos, alterando a estrutura e distribuição da comunidade; porém, organismos da família Chironomidae apresentam adaptações morfológicas ou fisiológicas especiais, que os tornam mais tolerantes às baixas concentrações de oxigênio.
A matéria orgânica relacionou-se com praticamente todas as ordens, com exceção de Odonata e Acari, sendo uma variável de extrema importância na dinâmica dessas comunidades no ambiente aquático, explicando a distribuição das mesmas no ambiente estudado.

Observa-se que os resultados encontrados foram influenciados pela quantidade de chuva registrada no local no período estudado, pela quantidade de matéria orgânica registrada no sedimento e principalmente pelas características do local, onde a ausência da mata ciliar e as ações antrópicas na região foram determinantes para os resultados encontrados.

\section{REFERÊNCIAS}

ABURAYA, F. H.; CALLIL, C. T. Variação temporal de larvas de Chironomidae (Diptera) no Alto Rio Paraguai (Cáceres, Mato Grosso, Brasil. Revista Brasileira de Zoologia, v. 24, n. 3, 2007.

ALLAN, J. D.; ERICKSON, D.L.;FAY, J. The influence of catchment land use on stream integrity across multiple spatial scale. Freshwater Biol, v. 37, p. 149-161, 1997.

BILLY, V. C.; REYES-MARCHANT, P; LAIR, N. \& VALADAS, B. Impacto f agricultural practices on a small headwater stream: terrestrial and aquatic characteristics and selfpurifying processes.

Hidrobiologia. 421: 129-139. 2000.

BRITO, R. N. R. de et al . Características sedimentares fluviais associadas ao grau de reservação da mata Ciliar - Rio Urumajó, Nordeste Paraense. Acta Amaz., Manaus, v. 39, n. 1, Mar. 2009.

CALliSTO, M.. ESTEVES, F. A. Composição Granulométrica do Sedimento de um Lago Amazônico Impactado por rejeito de Bauxita e um Lago Natural (Para, Brasil). Acta Limnologia

Brasiliensis, 1996, v.8, p. 115-126. 


\section{CALLISTO, M.; ESTEVES, F. A.}

Biomonitoramento da macrofauna bentônica de Chironomidae (Diptera) em dois igarapés amazônicos sob influência das atividades de uma mineração de bauxita. p. 299-309. In: Ecologia de insetos aquáticos. Rio de Janeiro, PPGE-UFRJ, Série Oecologia Brasiliensis, 309p, 1998.

CLEMENTS, W. H. Integrating effects of contaminats across levels of biological organization. J. Ecosy Stress and Rec., v. 7, p. 113-116, 2000.

CORBI, J. J.; STRIXINO, S. T.; SANTOS, A. do; DEL GRANDE, M. Diagnóstico ambiental de metais e organoclorados em córregos adjacentes da áreas de cultivo de cana de-açúcar (estado de São Paulo, Brasil). Quim. Nova, v. 29, n. 1, p. 61-65, 2006.

\section{EGLER, M. Utilizando a Comunidade de} Macroinvertebrados Bentônicos na Avaliação da Degradação de Ecossistemas de Rios em Áreas Agrícolas. 2002. Dissertação (Mestrado em Saúde Pública) - Escola Nacional de Saúde Pública, FIOCRUZ. Rio de Janeiro-RJ.

GOULART, M.; CALLISTO, M. Bioindicadores de qualidade de água como ferramenta em estudos de impacto ambiental. Revista da FAPAM, v. 2, n. 1. P. 153-164, 2003.

HÅKANSON, L. \& JANSSON, M. Principles of lake sedimentology. Springr-Verlag, Berlim. 1983. HIRABAYASHI K.; R. S. WOTTON. Organic matter processing by Chironomidae larvae (Diptera: Chironomidae). Hydrobiologia, v. 382, p. 151159, 1998.

MORETTI, M. S. \& CALLISTO, M.

Biomonitoring of benthic macroinvertebrates in the middle Doce river watershed. Acta Limnol. Bras. 17 (3): 267-281. 2005.
MOZETO, A. A.; UMBUSZEIRO, G. A. \& JARDIM, W. F. Métodos da coleta, análises físico-químicas e ensaios biológicos de sedimentos de água doce. São Carlos: Cuba. 2006.

OLIVEIRA, P. C. dos R. Comunidade de Macroinvertebrados Bentônicos e Qualidade da Água e do Sedimento das Bacias Hidrográficas dos rios Lavapés, Capivara, Araquá e Pardo, Município de Botucatu (SP) e região. 2009. Dissertação (Mestrado em Zoologia). UNESP, Botucatu-SP.

ONGLEY, E. D. Matching water quality programs to management needs in developing countries: The challenge of program modernization. Europe an Water Pollution Control, v. 7, n. 4, p. 43-48, 1997.

RICKLEFS, R. E. A economia da natureza. Rio de Janeiro: Guanabara Koogan, 2003. 501p.

RODRIGUES, F. A. C.; WEBER, O. L. S.; DORES, E. F. G. C.; KLATAUGUIMARÃES, M. N.; TILDON, R.; GRISÓLIA, C. K.

Ecogenotoxiogia dos agrotóxicos: Avaliação comparativa entre ecossistema agrícola e área de proteção ambiental. Pesticidas: revista de ecotoxicologia e meio ambiente, v. 15, p. 7384, 2005.

ROQUE, F.O.; TRIVINHO-STRIXINO, S.; STRIXINO, G.; AGOSTINHO, R.C. E FOGO, J.C. (2003), Benthic macroinvertebrates in streams of the Jaraguá State Park (Southeast of Brazil) considering multilple spatial scales. Journal of Insect Conservation, 7, 63-72.

TUNDISI, J.G.; TUNISI, T. M. \& ROCHA, O. Ecossistemas de águas interiores. In: Águas doces no Brasil: capital ecológico, uso e conservação. São Paulo, REBOUÇAS, A.C.; BRAGA, B. \& 
Variação espaço-temporal na abundância de ordens e famílias...

TUNDISI, J.G. 2006. 749 p.

WARD, J.V. Aquatic insect ecology: biology and habitat. New York: John Willey \& Sons,
1992. $438 \mathrm{p}$.

WETZEL, R. G. Limnology. New York. W. B.

Saunders Co., 743 p. 1975.

ReCEBIDO EM 7/10/2012

Асегто Eм 1/7/2013 
